Check for updates

Cite this: RSC Adv., 2019, 9, 27083

Received 15th July 2019

Accepted 14th August 2019

DOI: $10.1039 / c 9 r a 05417 k$

rsc.li/rsc-advances

\section{Enhanced fungicidal efficacy on Ganoderma boninense by simultaneous co-delivery of hexaconazole and dazomet from their chitosan nanoparticles}

\author{
Farhatun Najat Maluin, (D) a Mohd Zobir Hussein, ${ }^{\text {*a }}$ Nor Azah Yusof, ab \\ Sharida Fakurazi, ${ }^{c}$ Idris Abu Seman, ${ }^{d}$ Nur Hailini Zainol Hilmi ${ }^{d}$ \\ and Leona Daniela Jeffery Daim ${ }^{\mathrm{e}}$
}

\begin{abstract}
The excessive use of fungicides may be of environmental and health concerns. Hence, to overcome this problem, chitosan as a controlled release matrix was used in this work to encapsulate the fungicide for the development of enhanced fungicide nanodelivery system. In this proposed study, dual-loaded fungicides (hexaconazole and dazomet) were simultaneously encapsulated into chitosan nanoparticles as an antifungal agent on Ganoderma boninense (G. boninense). In this work, we report the synthesis and characterization of the nanoparticles prepared using various concentrations of the crosslinking agent of sodium tripolyphosphate (TPP); 2.5, 5, 10, and $20 \mathrm{mg}$ $\mathrm{mL}^{-1}$, which resulted in the nanoparticles of CHDEN2.5, CHDEN5, CHDEN10, and CHDEN20, respectively. The effect of TPP on the synthesized nanoparticle size revealed that an increase of TPP resulted in smaller particles, which in turn play a crucial role in controlling G. boninense growth. CHDEN20 shows the highest antifungal efficacy with the lowest half-maximal effective concentration $\left(E C_{50}\right.$ ) on $G$. boninense. The formulated nanocarrier system of fungicide aims to enhance the efficient delivery of the active ingredients to the target site, able to sustain in it for a longer time, and consequently improve the fungicide efficacy in combating the basal stem rot disease in oil palm.
\end{abstract}

\section{Introduction}

Palm oil emerges as the most profitable and efficient vegetable oilseed versus other world leading oilseeds, such as sunflower, coconut, rapeseed, and soybean. This is due to the high yield of oil palm where a hectare can produce up to ten times the oil compared to other oilseeds. ${ }^{1}$ In respect to that, Indonesia and Malaysia are the leading countries in oil palm production. ${ }^{2,3}$ However, oil palm cultivation is threatened by the most devastating disease, the basal stem rot (BSR) disease caused by Ganoderma boninense ( $G$. boninense) and

\footnotetext{
${ }^{a}$ Institute of Advanced Technology, Universiti Putra Malaysia, 43400 UPM, Serdang, Selangor, Malaysia. E-mail: mzobir@upm.edu.my; Tel: +6038946 8092

${ }^{b}$ Department of Chemistry, Faculty of Science, Universiti Putra Malaysia, 43400 UPM, Serdang, Selangor, Malaysia

${ }^{c}$ Department of Human Anatomy, Faculty of Medicine and Health Sciences, Universiti Putra Malaysia, 43400 UPM, Serdang, Selangor, Malaysia

${ }^{d}$ Malaysian Palm Oil Board (MPOB), 6, Persiaran Institusi, Bandar Baru Bangi, 43000, Kajang, Selangor, Malaysia

'Sime Darby Technology Centre Sdn. Bhd., UPM-MTDC Technology Centre III, Universiti Putra Malaysia, Lebuh Silikon, 1st Floor, Block B, 43400 Serdang, Selangor, Malaysia
}

has subsequently become the major concern in the oil palm industry. ${ }^{4-6}$

Previous studies have shown that fungicidal treatments of hexaconazole ${ }^{7,8}$ and dazomet ${ }^{9}$ were effective against the Ganoderma disease in oil palms. Hexaconazole is classified under the triazole group, widely used on cereal and ornamental plants to control fungi, particularly Ascomycetes and Basidiomycetes. ${ }^{10-12}$ It has systemic demethylation inhibitors (DMI) that act mainly on the vegetative stage of fungi by blocking the mycelial growth either inside or on the surface of the host plant. ${ }^{13}$ In addition, dazomet is a soil fumigant that releases methyl isothiocyanate (MITC) when it comes into contact with water. ${ }^{14,15}$ This MITC has been reportedly used in a broad spectrum of activities, such as inhibiting the activity of pathogenic fungi. ${ }^{16-18}$

However, it is also reported that the application of fungicides has caused environmental and health concerns, hence are a threat to both terrestrial and aquatic life as it is dissipated and leached. ${ }^{19,20}$ Thus, to address this issue, the fungicide was encapsulated in a nanocarrier of chitosan to develop an effective formulation nanodelivery system. The nanodelivery system aims to improve the solubility and stability, minimize volatilization, and enhance uptake with controlled release properties 
to give a high efficiency as the fungicide active ingredient can reach the target fungus, $G$. boninense, more effectively. ${ }^{21-24}$

Numerous studies have been conducted on the use of chitosan in plant protection, but only limited studies have been reported in the use of chitosan in agronanoparticles. ${ }^{25}$ Apart from non-toxicity, biodegradability, biocompatibility, and antimicrobial and antioxidant activity, chitosans are known for their ability to control or reduce the spreading of disease in the plant by inhibiting pathogens and enhance the plant defense mechanism..$^{26,27}$ In addition, dual encapsulation had been proven to increase the drug release and bioavailability, but the formulation might be challenging due to the drugs incompatibility that could give rise to complications. ${ }^{28}$

This study aims to synthesize and characterize the hostguest type nanoparticles by combining the chitosan with fungicide molecules through chemical reactions, hoping that the resulting nanoparticles have a slow-release capability, low toxicity, and high antifungal activity against $G$. boninense. The chitosan nanoparticles were embedded simultaneously with hexaconazole and dazomet (CHDEN) using an ionic gelation method by adding several concentrations of the crosslinking agent, sodium tripolyphosphate (TPP). The effect of TPP on the formation of chitosan-hexaconazole-dazomet nanoparticles was investigated, namely the particle size distribution, loading capacity, and encapsulation efficiency of the fungicides. In addition, the relationship between the particle size of the synthesized chitosan-hexaconazole-dazomet nanoparticles and in vitro antifungal activity against $G$. boninense also was investigated. The co-release profiles of both hexaconazole and dazomet from the synthesized nanoparticles were also studied.

An encapsulation mechanism of both hexaconazole and dazomet in the chitosan matrix is proposed in Fig. 1. The fungicides were embedded first by separately mixing hexaconazole and dazomet with the chitosan solution. Then, both solutions were mixed together before adding the Tween80 and TPP solution, prior to the formation of the nanoparticles. The nanoparticles were formed through the electrostatic interaction between the embedded fungicides in the positively charged amine group of chitosan and the negatively charged crosslinker of TPP using an ionic gelation method. Tween-80 was added as a stabilizing agent for the formation of nanoparticles. Moreover, TPP has also been reported to be used in controlling nanoparticles size and drug loading. ${ }^{27,28}$

\section{Material and methods}

\section{Materials}

Hexaconazole $\left(\mathrm{C}_{14} \mathrm{H}_{17} \mathrm{Cl}_{2} \mathrm{~N}_{3} \mathrm{O}\right.$, molecular weight $314.21 \mathrm{~g}$ $\left.\mathrm{mol}^{-1}\right)$ and dazomet $\left(\mathrm{C}_{5} \mathrm{H}_{10} \mathrm{~N}_{2} \mathrm{~S}_{2}\right.$, molecular weight $162.269 \mathrm{~g}$ $\mathrm{mol}^{-1}$ ) were purchased from Changzhou Aiteng with 95\% purity and were used as received. Chitosan (medium molecular weight, 190 000-310 000 degree of acetylation), Tween-80 and sodium tripolyphosphate (TPP) were purchased from Sigma-Aldrich [St. Louis, MO, USA]. Hydrochloric acid (37\%) and $N, N$-dimethylformamide (DMF) were purchased from Friendemann Schmidt [Parkwood, Australia] and Merck [Kenilworth, NJ, USA], respectively. All the other reagents used were of analytical grade. The G. boninense culture was provided by the Malaysian Palm Oil Board (MPOB), Bangi, Malaysia, and maintained in potato dextrose agar (PDA) media purchased from Oxoid, Thermo Scientific ( $\mathrm{pH}$ 5.5) [Waltham, MA, USA] incubated at $28 \pm 2{ }^{\circ} \mathrm{C}$.

\section{Preparation of chitosan-hexaconazole-dazomet nanoparticles}

Hexaconazole-dazomet-loaded chitosan nanoparticles were prepared using ionic gelation method. ${ }^{29,30}$ Briefly, $5 \mathrm{mg} \mathrm{mL} \mathrm{m}^{-1}$ of chitosan was prepared in $100 \mathrm{~mL}$ of a $1.0 \%(\mathrm{v} / \mathrm{v})$ acetic acid solution and, in a different flask, $10 \mathrm{mg} \mathrm{mL}^{-1}$ of hexaconazole and dazomet were prepared in $100 \mathrm{~mL}$ of DMF separately. Then, all the solutions were mixed together under stirring until a homogeneous solution was obtained. Then, $2 \% \mathrm{v} / \mathrm{v}$ Tween-80 was added as a stabilizer to prevent particle aggregation. $^{31,32}$ Various concentrations of sodium TPP ranging from $2.5,5,10$, and $20 \mathrm{mg} \mathrm{mL}^{-1}$ were used and the resulting nanoparticles labeled as CHDEN2.5, CHDEN5, CHDEN10, and CHDEN20, respectively. The nanoparticles were formed spontaneously upon the addition of $40 \mathrm{~mL}$ sodium TPP solution added dropwise using a burette while stirring. The final TPP-to-chitosan ratio achieved was $1: 2.5(\mathrm{v} / \mathrm{v})$. The mixture was then centrifuged at $40000 \mathrm{rpm}$ for $10 \mathrm{~min}$ and the supernatant was discarded. The chitosan-hexaconazoledazomet nanoparticle pellet was then freeze-dried overnight before further analysis.
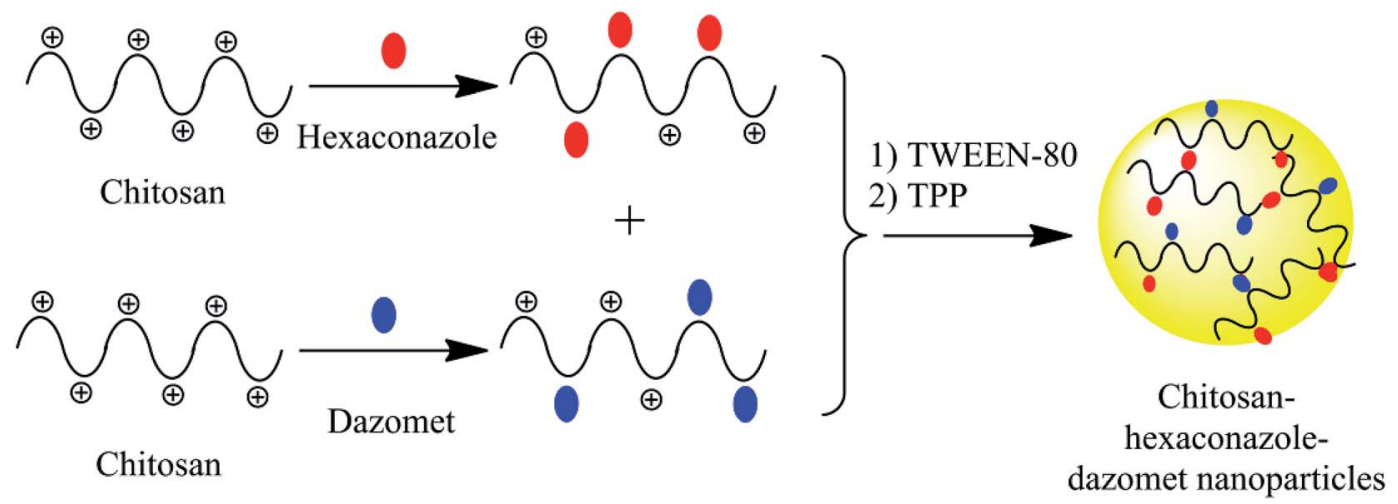

Fig. 1 Proposed mechanism for the formation of chitosan-hexaconazole-dazomet nanoparticles. 


\section{Reaction yield, fungicide loading, and encapsulation efficiency}

The reaction yield of the synthesized chitosan-hexaconazoledazomet nanoparticles was calculated using eqn (1)..$^{29,30}$

$\mathrm{RY}=[$ produced nanoparticle $(\mathrm{mg}) /($ used chitosan $(\mathrm{mg})+$ used dazomet $(\mathrm{mg})+$ used hexaconazole $(\mathrm{mg}))] \times 100$

The hexaconazole and dazomet loading content (LC) and encapsulation efficiency (EE) were determined using the highperformance liquid chromatography (HPLC) technique. Briefly, $5.0 \mathrm{mg}$ of the synthesized nanoparticles were dissolved in $10.0 \mathrm{~mL}$ of methanol and hydrochloric acid $(0.5 \% \mathrm{v} / \mathrm{v})$ under sonication, and a clear solution was obtained prior to the HPLC analysis. The nanoparticles were ensured to be completely dissolved, thus releasing $100 \%$ of the hexaconazole and dazomet content. The mobile phase of the HPLC used was methanol/water $(30: 70, \mathrm{v} / \mathrm{v})$,

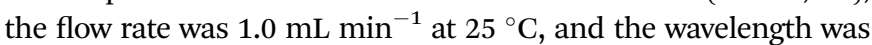
set at 235 and $280 \mathrm{~nm}$ for hexaconazole and dazomet, respectively. The retention time obtained was 1.8 and $2.5 \mathrm{~min}$ for hexaconazole and dazomet, respectively. The LC and EE of the hexaconazole and dazomet were calculated according to the following equations:

LC $(\%)=$ [weight of fungicide in nanoparticles/weight of nanoparticles] $\times 100$

$\mathrm{EE}(\%)=$ [weight of fungicide in nanoparticles/initial amount of fungicide in the system] $\times 100$

\section{Fungicide release studies}

The hexaconazole and dazomet release profile from the nanoparticles was investigated using HPLC. Briefly, $30.0 \mathrm{mg}$ of the synthesized nanoparticles were dispersed in $30 \mathrm{~mL}$ of the medium and shaken in incubator shaker $\left(27^{\circ} \mathrm{C} ; 100 \mathrm{rpm}\right)$ in a phosphate-buffered saline solution (PBS), pH 5.5. The buffer solution of $\mathrm{pH} 5.5$ was chosen in this experiment in order to imitate the release of fungicide in the potato dextrose agar (PDA) media. At predetermined intervals time, $1 \mathrm{~mL}$ of the solution was isolated by centrifugation and replaced with the same amount of the fresh medium. The concentrations of the released hexaconazole and dazomet were determined by HPLC as described above.

\section{Characterizations}

Fourier transform infrared spectra (FTIR), powder X-ray diffraction (PXRD) and thermogravimetric and differential thermogravimetric analysis (TGA/DTG) techniques were used to characterize the structure of the synthesized nanoparticles. ${ }^{27,28}$ The FTIR study was carried out with a Thermo Nicolet Nexus spectrometer with a Smart Orbit, in the range 400-4000 $\mathrm{cm}^{-1}$ (Waltham, MA, USA). The phase and purity studies were performed with an XRD technique using a Bruker D8 Advance powder XRD using $\mathrm{CuK}_{\alpha}$ radiation $(\lambda=0.15406 \mathrm{~nm})$ at $40 \mathrm{kV}$ and $40 \mathrm{~mA}$ (Billerica, MA, USA). The thermal stability and decomposition were done by a thermal gravimetric analyzer, a Mettler-Toledo $851 \mathrm{e}$, at a heating rate of $10^{\circ} \mathrm{C} \min ^{-1}$ in $150 \mu \mathrm{L}$ alumina crucibles over the range $30-900{ }^{\circ} \mathrm{C}$ (Columbus, $\mathrm{OH}$, USA).

The hydrodynamics particle size was determined by a dynamic light scattering (DLS) method using a particle size analyzer (Nano Series Nano-ZS, Malvern Panalytical Ltd., Malvern, UK). The internal morphology and particle size diameter were studied using a high-resolution transmission electron microscope (HRTEM), FEI Tecnai G2 F20 S-TWIN (Hillsboro, OR, USA). The surface morphology analysis was conducted using field-emission scanning electron microscopy (FESEM), JSM-7500F JEOL, Tokyo, Japan.

The amount of fungicide loading and release was measured using a high-performance liquid chromatography (HPLC) Waters Alliance 2695 separation module (Waters, Milford, MA, USA). HPLC assays were conducted at room temperature $\left(23^{\circ} \mathrm{C}\right)$ with a diode array detector Waters 2996. The mobile phase of a $30: 70(\mathrm{v} / \mathrm{v})$ methanol : water solution and a C18 column (5 $\mu \mathrm{m}, 4.6 \times 150 \mathrm{~mm})$ was employed. ${ }^{27}$

\section{In vitro antifungal activity efficacy studies}

The in vitro antifungal activity of the synthesized nanoparticles was evaluated against $G$. boninense using a poisoned medium technique with potato dextrose agar (PDA) as the medium. The PDA was amended in seven different conditions (pure hexaconazole, pure dazomet, chitosan, and the synthesized nanoparticles, CHDEN2.5, CHDEN5, CHDEN10 and CHDEN20) at several concentrations $(0.1,0.5,1,5,10,50,100,500$ and $1000 \mathrm{ppb}$ of active ingredient), which were prepared in acetone and $0.5 \%(\mathrm{v} / \mathrm{v}) \mathrm{HCl}$. Mycelia plated on the PDA with the solvent only served as a control. A $5 \mathrm{~mm}$ mycelial disc from the margins of the actively growing culture of $G$. boninense was placed at the center of amended PDA as well as in the non-amended PDA. The radial growth of the mycelia was measured for 7 days of inoculation by incubating the Petri plates at $28 \pm 2{ }^{\circ} \mathrm{C}(n=5)$. Mycelial growth was recorded every day. The percentage inhibition of the radial growth (PIRG) by the fungicide was then calculated.

\section{Statistical analysis}

Data are presented as mean \pm standard deviation and the statistical difference of the parameters was analyzed using ANOVA and Tukey's test $(p \leq 0.05)$ using SPSS software. The half-maximal effective concentration $\left(\mathrm{EC}_{50}\right)$ of chitosan-hexaconazole-dazomet nanoparticles at various concentrations of TPP were determined using the sigma plot analysis of Sigma Plot 10.0.

\section{Results and discussions}

\section{Reaction yield, fungicide loading, and encapsulation efficiency}

As listed in Table 1, there is no significant difference in the loading content and encapsulation efficiency of both hexaconazole and dazomet in the synthesized nanoparticles prepared at various concentrations of TPP. This suggests that there is no effect of TPP concentration on the loading content of 
Table 1 Loading content and encapsulation efficiency of fungicide in the synthesized nanoparticles

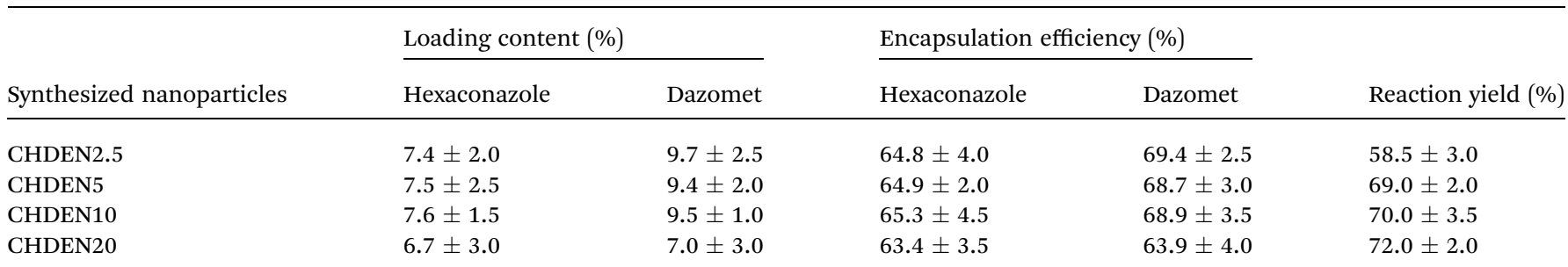

both hexaconazole and dazomet in the preparation of chitosanhexaconazole-dazomet nanoparticles. On the other hand, the amount of dazomet in the synthesized nanoparticles exhibited a higher loading content and encapsulation efficiency compared to the amount of hexaconazole, thus suggesting that dazomet has a higher capability to be encapsulated into the chitosan matrix, compared to the hexaconazole. This behavior is also supported by our previous work on a single loaded system of chitosan-hexaconazole nanoparticles ${ }^{29}$ and chitosandazomet nanoparticles. ${ }^{30}$ This might be due to the smaller molecular structure of dazomet compared to hexaconazole (Fig. 2), hence making it much easier to form hydrogen bonding with the chitosan. Moreover, the reaction yield of the hexaconazole-dazomet-loaded chitosan reached an optimum at $5 \mathrm{mg} \mathrm{mL}{ }^{-1}$, where the increase of TPP at 10 and $20 \mathrm{mg} \mathrm{mL}^{-1}$ no longer affected the yield.

\section{Powder X-ray diffraction}

As shown in Fig. 3, pure dazomet and pure hexaconazole showed a sharp peak suggesting that they are highly crystalline in nature. Meanwhile, chitosan showed a broad peak showing it is an amorphous type of material. For the nanoparticles, CHDEN2.5, CHDEN5, CHDEN10 and CHDEN20, broad peaks of an amorphous type are observed, suggesting a high content of the chitosan phase, in which the crystalline peaks of dazomet and hexaconazole were buried when they were encapsulated within the chitosan nanoparticles. The broad peak at diffraction angles $(2 \theta)$ of 16.1, 19.2, 20.8, 22.7, 29.1, and $36.0^{\circ}$ matched with the peak pattern of pure dazomet, while diffraction angles $(2 \theta)$ of 8.4, 10.4, 11.7, 13.9, 16.0, 20.2, and $24.0^{\circ}$ matched the peak pattern of pure hexaconazole, thus inferring the encapsulation of both dazomet and hexaconazole into the chitosan matrix.

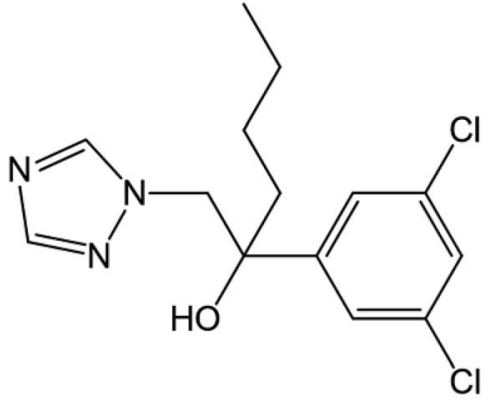

Hexaconazole

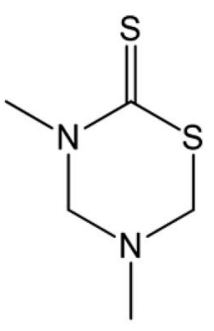

Dazomet
Fig. 2 Chemical structures of hexaconazole and dazomet.

\section{FTIR spectroscopy}

As shown in Fig. 4, broad bands at $2870 \mathrm{~cm}^{-1}$ and $3288 \mathrm{~cm}^{-1}$ were due to the $\mathrm{C}-\mathrm{H}$ bond and $\mathrm{NH}_{2}$ stretching of the chitosan, respectively. ${ }^{33}$ Chitosan also showed characteristic broad bands at 1022, 1588, and $1647 \mathrm{~cm}^{-1}$, which indicated the stretching of the $\mathrm{C}-\mathrm{O}-\mathrm{C}$ moiety, $\mathrm{NH}_{2}$ group bending, and $\mathrm{CO}-\mathrm{NH}_{2}$ group stretching, respectively. ${ }^{33}$ Besides, all the synthesized nanoparticles showed the characteristic peak of chitosan with a slight shifting of $\mathrm{NH}_{2}$ peak at $1536 \mathrm{~cm}^{-1}$. The shifting might be due to the presence of $\mathrm{N}-\mathrm{H}$ bending from the dazomet, which is at $1513 \mathrm{~cm}^{-134}$. Moreover, additional bands of dazomet for the synthesized nanoparticles have also been observed at 1176 and $657 \mathrm{~cm}^{-1}$, which can be attributed to the $\mathrm{C}=\mathrm{S}$ stretching and $\mathrm{C}-\mathrm{H}$ bending, respectively, of a 1,3,5-trisubstituted aromatic alkane. ${ }^{34,35}$ Apart from that, additional bands of hexaconazole can also be seen for the synthesized nanoparticles at 1384, 890, 806 and $657 \mathrm{~cm}^{-1}$, which can be attributed to C-N stretching, $\mathrm{C}=\mathrm{C}$ bending and $\mathrm{C}-\mathrm{Cl}$ stretching, respectively, ${ }^{36}$ and thus strongly support the encapsulation of both hexaconazole and dazomet into the host, chitosan, in all the CHDEN2.5, CHDEN5, CHDEN10, and CHDEN20.

\section{Thermal analysis}

Thermal stability of the synthesized nanoparticles was studied using a thermal analyzer, and the TGA/DTG thermograms and the data obtained are shown in Fig. 5. Chitosan showed two stages of weight loss at $65^{\circ} \mathrm{C}$ and $309^{\circ} \mathrm{C}$, which are attributed to

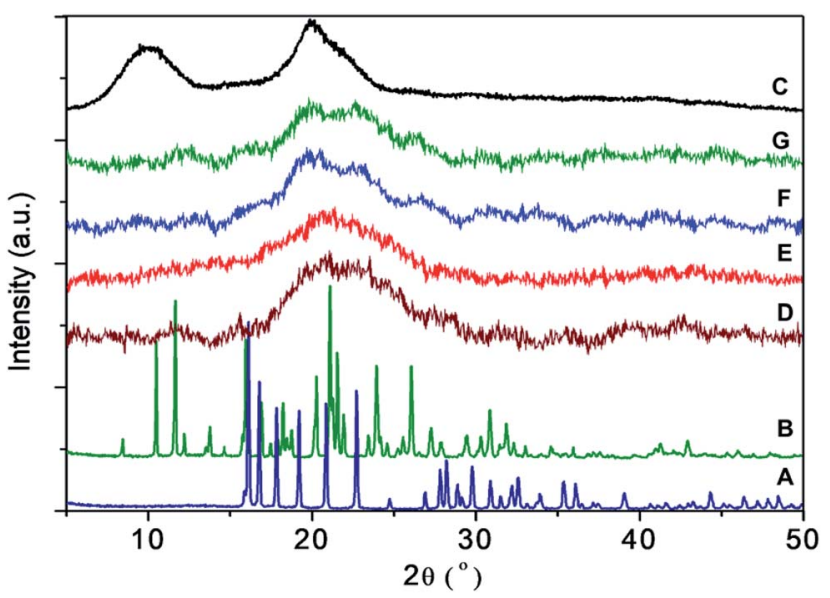

Fig. 3 PXRD patterns of (A) pure dazomet, (B) pure hexaconazole, (C) chitosan, and chitosan-hexaconazole-dazomet nanoparticles prepared at various concentrations of TPP (D) $2.5 \mathrm{mg} \mathrm{mL}^{-1}$, (E) $5 \mathrm{mg}$ $\mathrm{mL}^{-1}$, (F) $10 \mathrm{mg} \mathrm{mL}^{-1}$ and (G) $20 \mathrm{mg} \mathrm{mL}^{-1}$. 


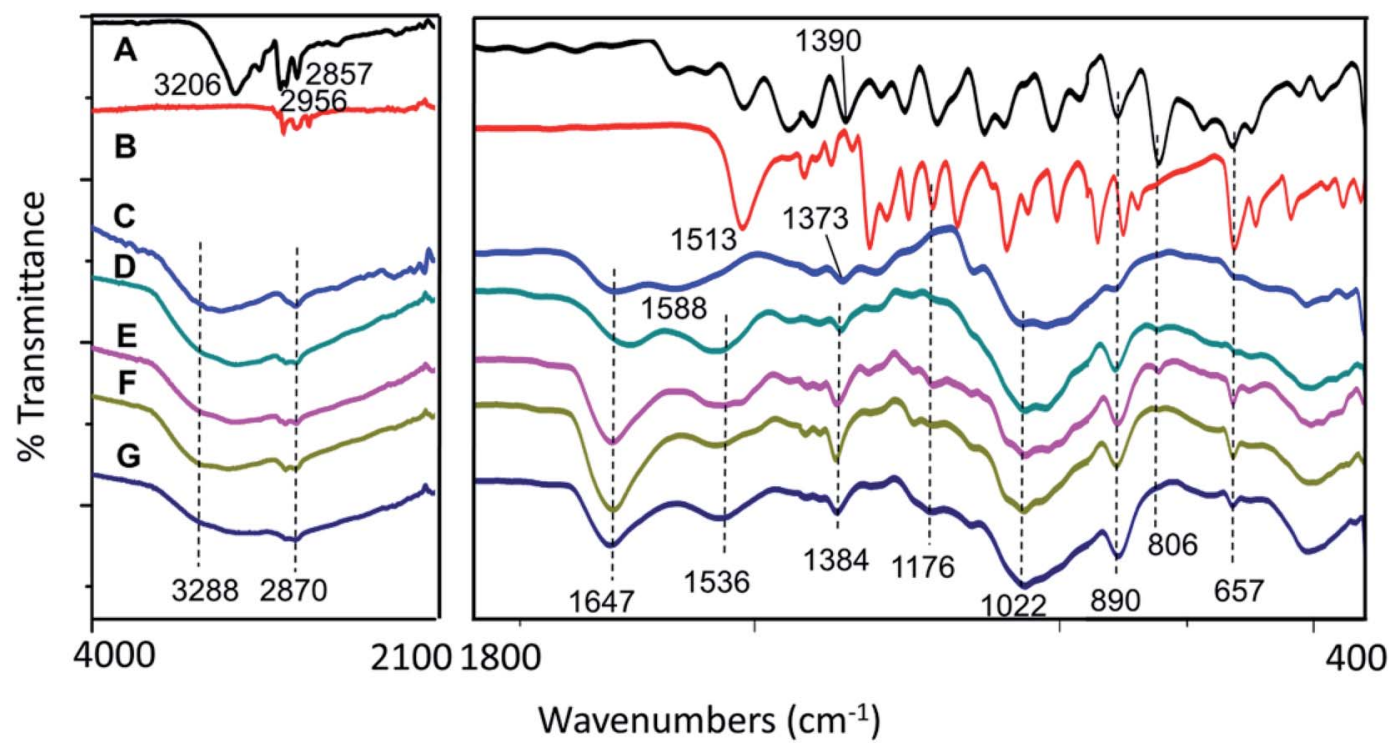

Fig. 4 FTIR spectrum of (A) pure hexaconazole, (B) pure dazomet, (C) chitosan, and chitosan-hexaconazole-dazomet nanoparticles prepared at various concentrations of TPP (D) $2.5 \mathrm{mg} \mathrm{mL}^{-1}$, (E) $5 \mathrm{mg} \mathrm{mL}^{-1}$, (F) $10 \mathrm{mg} \mathrm{mL}^{-1}$ and (G) $20 \mathrm{mg} \mathrm{mL}^{-1}$.

the release of the physical adsorption of the water molecules and decomposition of chitosan (loss of hydrogen bonding), respectively. In addition, at the end of the analysis, nearly $30 \%$ of the sample remained as a residue indicating a higher thermal stability of chitosan. Moreover, 100\% weight loss was obtained at $282{ }^{\circ} \mathrm{C}$ and $194{ }^{\circ} \mathrm{C}$ for pure hexaconazole and pure dazomet, respectively, which indicates the total decomposition of hexaconazole and dazomet. Hence, showing a higher thermal stability for pure hexaconazole compared to that of pure dazomet. This is presumably due to the more complex and bigger molecular structure of hexaconazole compared to dazomet (Fig. 2).

The synthesized nanoparticles showed four stages of weight loss. In the first stage, weight losses of approximately 14.0, 15.8, 12.6 and $18.5 \%$, respectively, for CHDEN2.5, CHDEN5, CHDEN10, and CHDEN20 occurred due to the release of water molecules. The second stage at around $245-255^{\circ} \mathrm{C}$ was attributed to the decomposition of chitosan. While at the third stage, the
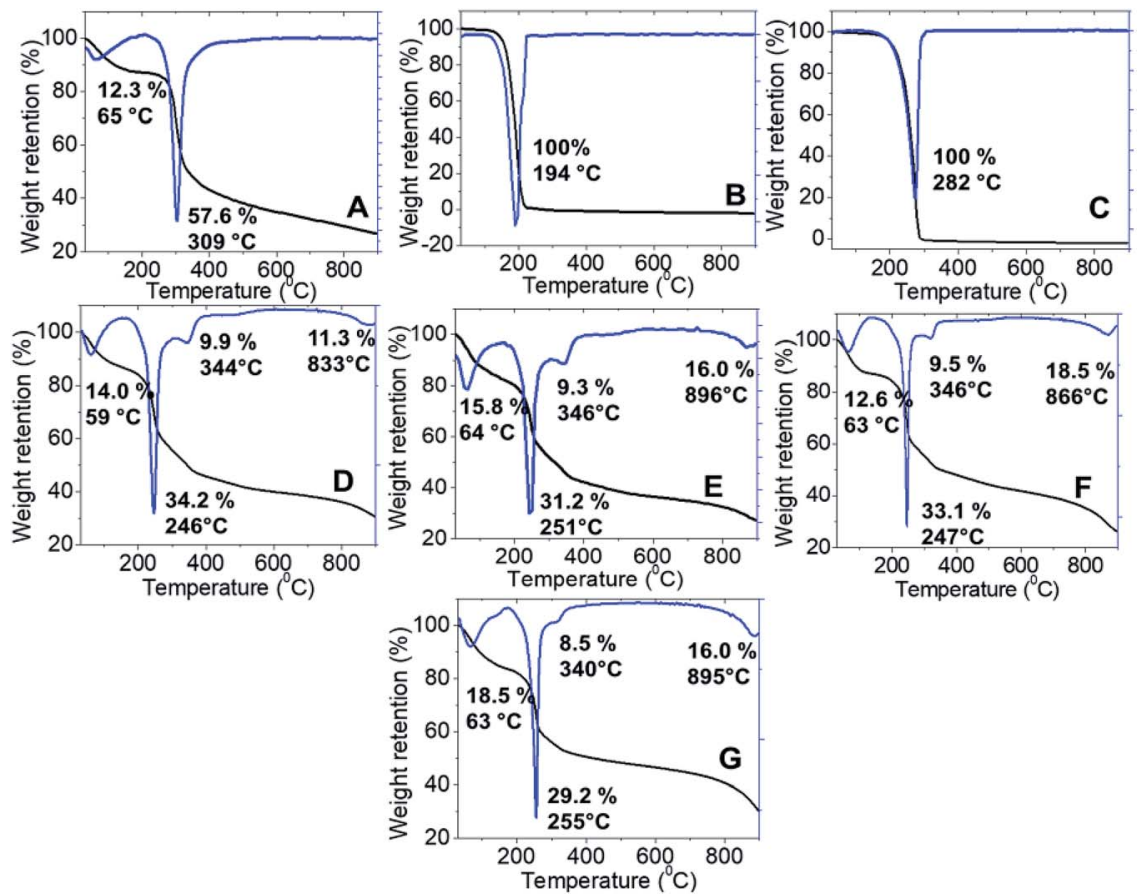

Fig. 5 TGA-DTG thermogram of (A) chitosan, (B) pure dazomet, (C) pure hexaconazole and chitosan-hexaconazole-dazomet nanoparticles prepared at various concentrations of TPP (D) $2.5 \mathrm{mg} \mathrm{mL}^{-1}$, (E) $5 \mathrm{mg} \mathrm{mL}^{-1}$, (F) $10 \mathrm{mg} \mathrm{mL}^{-1}$ and (G) $20 \mathrm{mg} \mathrm{mL}^{-1}$. 

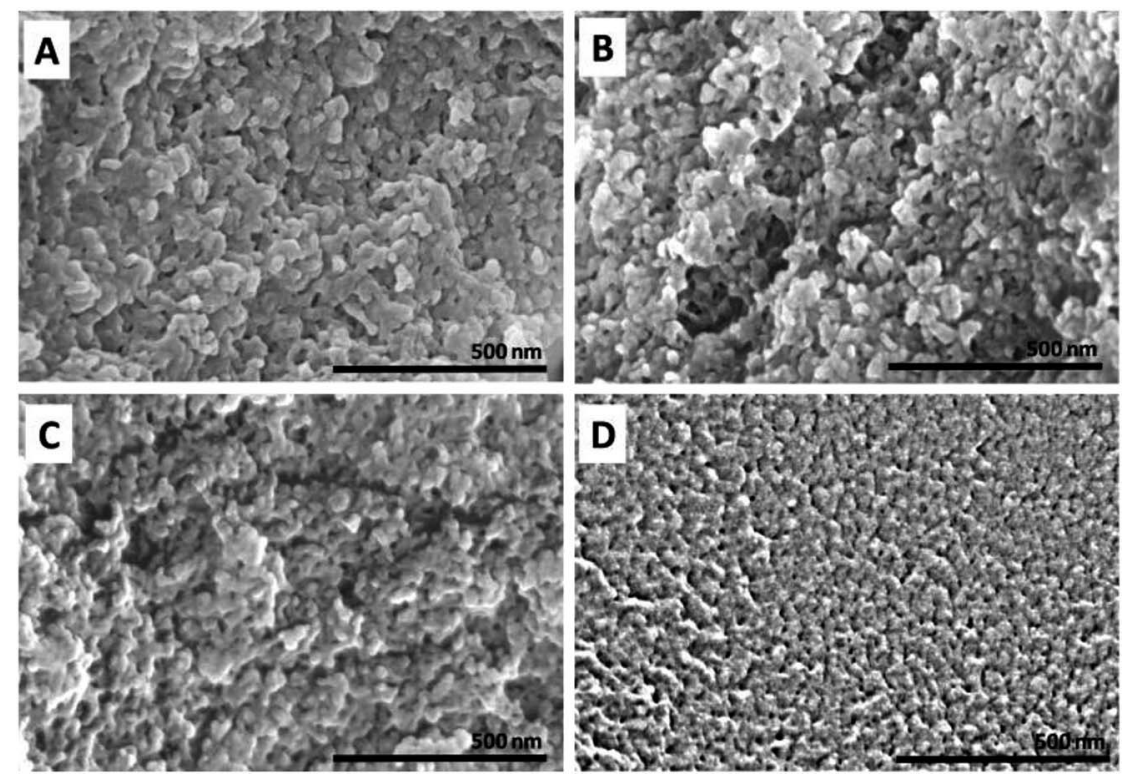

Fig. 6 FESEM image of chitosan-hexaconazole-dazomet nanoparticles prepared at various concentrations of TPP (A) $2.5 \mathrm{mg} \mathrm{mL}{ }^{-1}$, (B) $5 \mathrm{mg}^{-1}$ $\mathrm{mL}^{-1}$, (C) $10 \mathrm{mg} \mathrm{mL}^{-1}$ and (D) $20 \mathrm{mg} \mathrm{mL}^{-1}$.
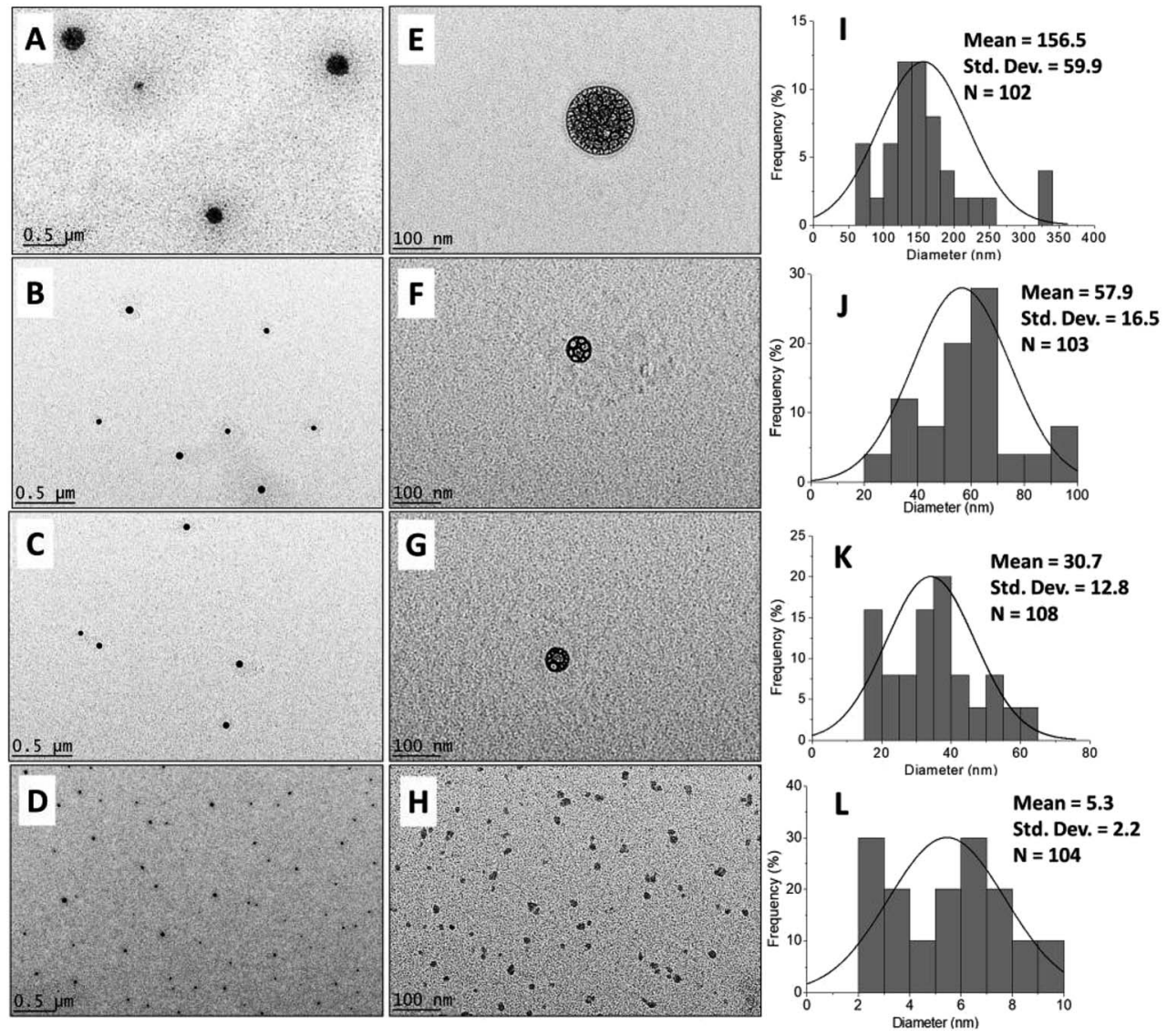

Fig. 7 HRTEM image at 4,500 $\times$ magnification (A-D) and 39,000 $\times$ magnification (E-H) of the chitosan-hexaconazole-dazomet nanoparticles prepared at various concentrations of TPP ( $A$ and E) $2.5 \mathrm{mg} \mathrm{mL}^{-1}$, (B and F) $5 \mathrm{mg} \mathrm{mL}^{-1}$, (C and G) $10 \mathrm{mg} \mathrm{mL}^{-1}$ and (D and H) $20 \mathrm{mg} \mathrm{mL}^{-1}$ and the particle size distribution of the chitosan-hexaconazole-dazomet nanoparticles prepared at various concentrations of TPP (I) $2.5 \mathrm{mg} \mathrm{mL}^{-1}$, (J) $5 \mathrm{mg} \mathrm{mL}^{-1}$, (K) $10 \mathrm{mg} \mathrm{mL}^{-1}$ and (L) $20 \mathrm{mg} \mathrm{mL}^{-1}$. 
synthesized nanoparticles of CHDEN2.5, CHDEN5, CHDEN10, and CHDEN20 showed a third weight loss at 344, 346, 346 and $340{ }^{\circ} \mathrm{C}$, respectively, attributed to a combination of dazomet and hexaconazole thermal decomposition. This shows the higher thermal stability of hexaconazole and dazomet in the synthesized nanoparticles compared to the bare fungicide, hexaconazole and dazomet. For the last stage at around $800{ }^{\circ} \mathrm{C}$, the weight loss is attributed to char from the decomposition of chitosan.

\section{Morphology and particle size distribution}

The morphological and particle size distribution of CHDEN2.5, CHDEN5, CHDEN10, and CHDEN20 were studied by FESEM (Fig. 6) and HRTEM (Fig. 7A-H), and their size distribution was measured via ImageJ software (Fig. 7I-L). The agglomeration of sphere shape can be seen in the FESEM image. Moreover, the internal morphology of the HRTEM images clearly shows the spherical shape of all the synthesized nanoparticles. The loaded of the fungicides inside the chitosan nanoparticles matrix can also be seen clearly for CHDEN2.5, CHDEN5, and CHDEN10 in the HRTEM image at a high magnification of $39000 \times$. The image is not clear for CHDEN20 since its size is too small. In addition, the results reveal the higher size range of the particle size distribution for the synthesized nanoparticles at the lowest concentration of TPP (CHDEN2.5) with a mean particle size of $156.5 \mathrm{~nm}$. The increased TPP concentration resulted in smaller particle sizes of the synthesized nanoparticles which follows the order: CHDEN5 > CHDEN10 > CHDEN20, with mean particle size of 57.9, 30.7 and $5.3 \mathrm{~nm}$, respectively.

Furthermore, the hydrodynamic size measured via dynamic light scattering (DLS) of the synthesized chitosan nanoparticles simultaneously loaded with both hexaconazole and dazomet, CHDEN2.5, CHDEN5, CHDEN10, and CHDEN20, are shown in Fig. 8. The findings of both methods indicate that the use of a higher concentration of TPP resulted in a smaller particles size of the synthesized nanoparticles. The presence of oppositely charged ions in the deionized water (solvent medium) leading to adsorption might be the reason for this phenomenon. The interaction between $-\mathrm{NH}_{3}{ }^{+}$of chitosan (protonated under acid conditions) with the multivalent anion, TPP, results in the formation of CS-TPP. Thus, a higher concentration of TPP means a higher number of anions, and hence more inter- and intramolecular cross-linking between the chitosan and TPP. Consequently, this leads to the formation of smaller particle sizes. ${ }^{37}$

\section{Fungicide release studies}

To investigate the delivery of hexaconazole and dazomet in response to time, the synthesized nanoparticles prepared at $5 \mathrm{mg} \mathrm{mL}{ }^{-1}$ TPP and $20 \mathrm{mg} \mathrm{mL}{ }^{-1}$ TPP, i.e. CHDEN5 and CHDEN20, respectively, were incubated in a phosphate buffer saline solution at $\mathrm{pH}$ 5.5. As shown in Fig. 9 and 10, a small burst effect can be observed in the first 11 hours for both release profiles of hexaconazole and dazomet in both CHDEN5 and CHDEN20. This may be because the fungicides were located close to the surface of the nanoparticles. In addition, a faster release of both hexaconazole and dazomet in CHDEN20 can be seen in the first 80 and 40 hours, respectively. However, surprisingly, the sustained releases of hexaconazole and dazomet in CHDEN20 were much longer with 130 hours (93.6\% cumulative release) and 50 hours (76.4\% cumulative release),
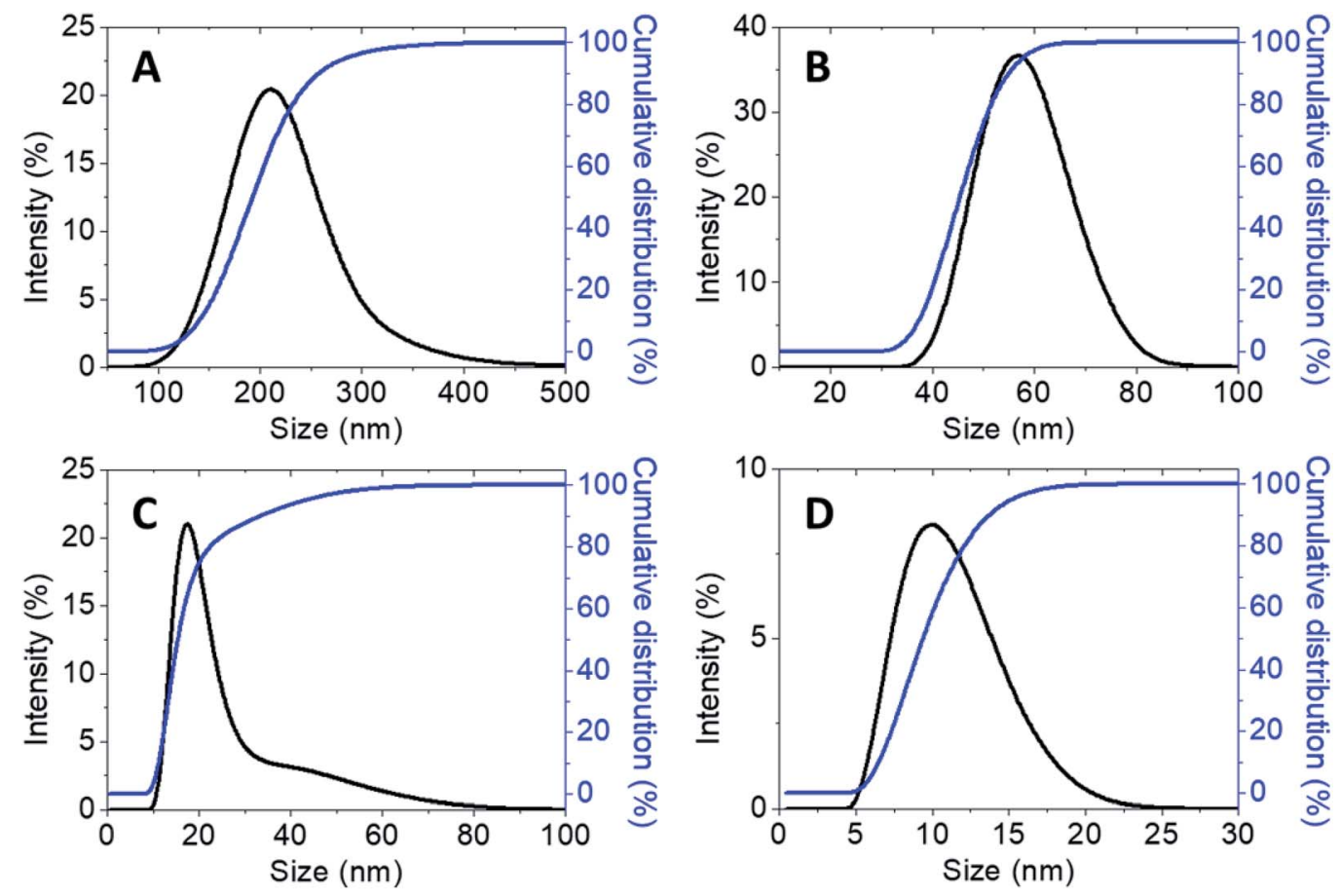

Fig. 8 Cumulative and relative particles size distributions (PSD) of chitosan-hexaconazole-dazomet nanoparticles prepared at various concentrations of TPP (A) $2.5 \mathrm{mg} \mathrm{mL}^{-1}$, (B) $5 \mathrm{mg} \mathrm{mL}^{-1}$, (C) $10 \mathrm{mg} \mathrm{mL}^{-1}$ and (D) $20 \mathrm{mg} \mathrm{mL}^{-1}$. 
A

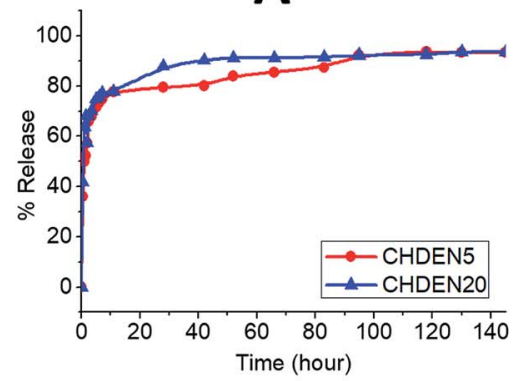

D

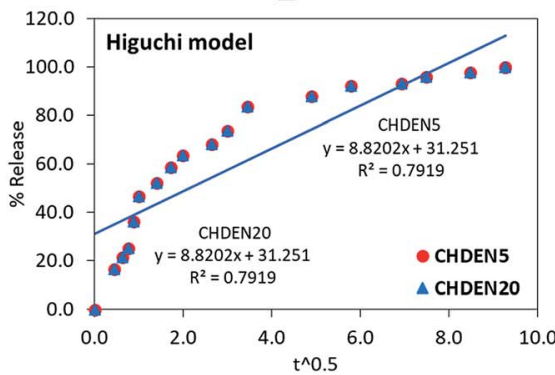

B

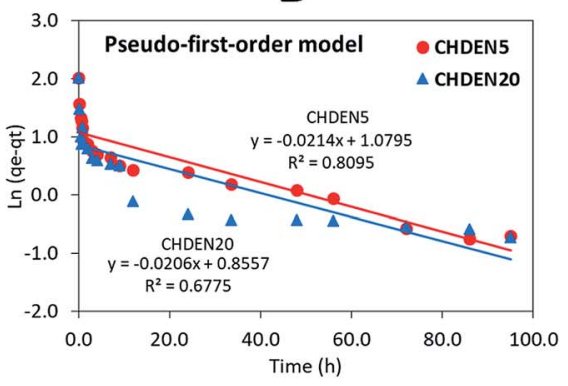

$\mathbf{E}$

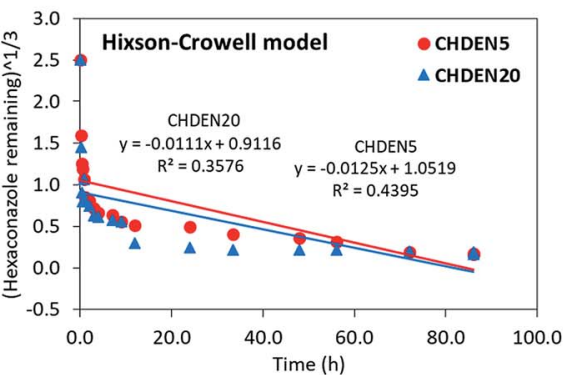

C

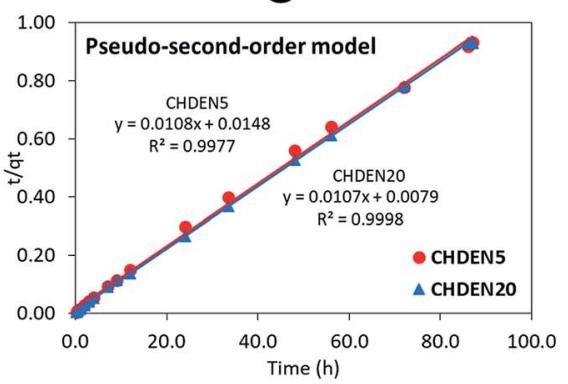

$\mathbf{F}$

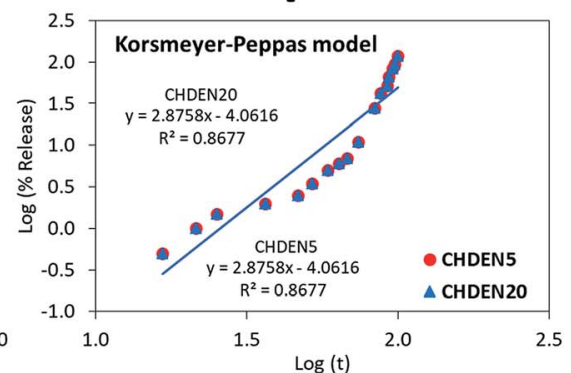

Fig. 9 Cumulative release profiles of (A) hexaconazole from CHDEN5 and CHDEN20 at pH 5.5 and (B-F) the fitting of the data using five different mathematical models at $\mathrm{pH} 5.5$.

respectively. In contrast, the sustained releases of hexaconazole and dazomet in CHDEN5 were achieved up to 118 hours $(93.7 \%$ cumulative release) and 42 hours (75.3\% cumulative release), respectively. This suggests a minimal effect of particle size in the dual release of hexaconazole and dazomet. However, it is worth noting that the release of both fungicides was a bit faster in the smaller particle size, but at the same time prolonged the fungicides release. This is due to the higher surface area of the smaller nanoparticle size.

By fitting the data of the hexaconazole and dazomet release from the nanoparticles into the five different kinetics and mathematical models, the linear fits of the model are presented

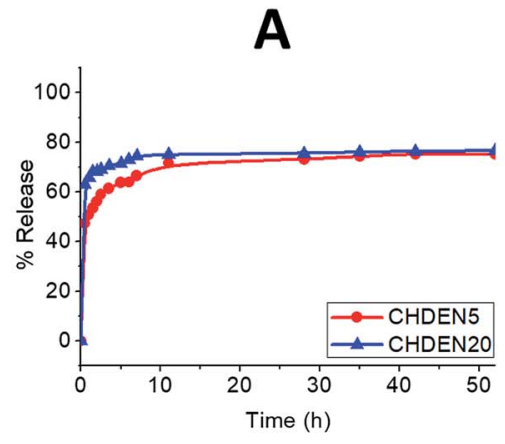

D

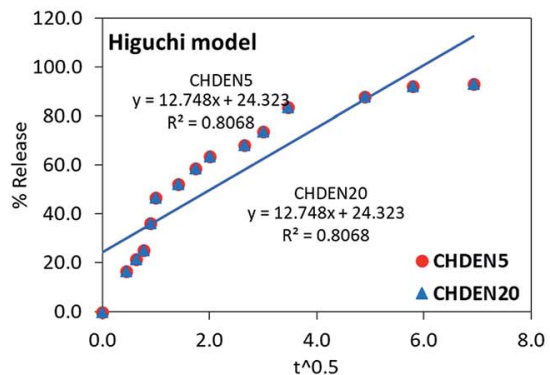

B

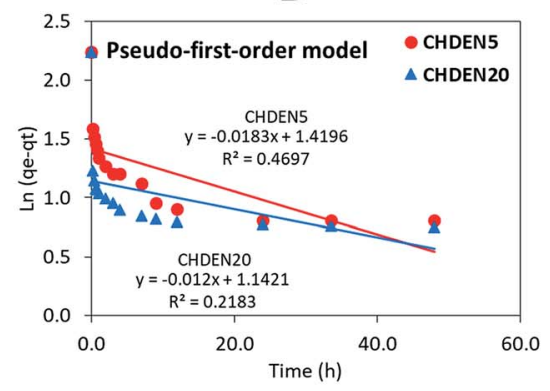

E

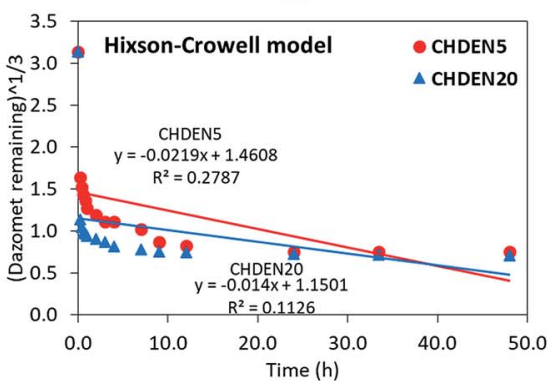

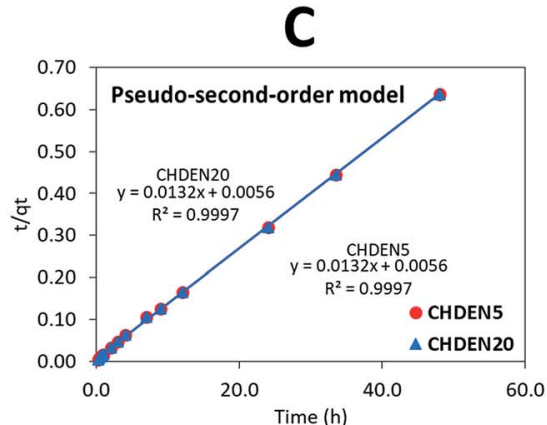

$\mathbf{F}$

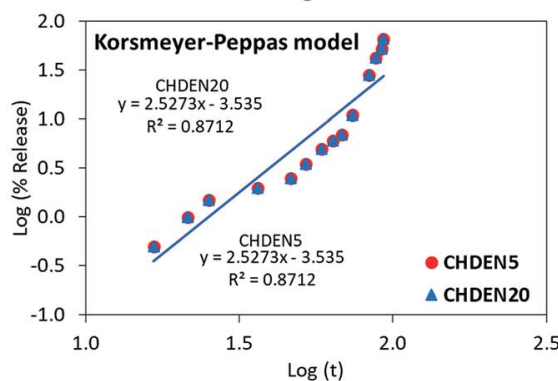

Fig. 10 Cumulative release profiles of (A) dazomet from CHDEN5 and CHDEN20 at pH 5.5 and (B-F) the fitting of the data using five different mathematical models at $\mathrm{pH} 5.5$. 
Table 2 Correlation coefficient, rate constant and half-life obtained by fitting the release data of hexaconazole and dazomet from CHDEN5 in phosphate buffer solution at $\mathrm{pH} 5.5$ using five different kinetic mathematical models

\begin{tabular}{|c|c|c|c|c|c|c|c|c|}
\hline \multirow[b]{2}{*}{ Fungicides } & \multirow[b]{2}{*}{ Nanoparticle } & \multicolumn{5}{|c|}{ Correlation coefficient, $R^{2}$} & \multirow{2}{*}{$\begin{array}{l}\text { Rate constant of } \\
\text { pseudo-second order, } \\
k\left(\mathrm{mg} \mathrm{h} \mathrm{h}^{-1}\right)\end{array}$} & \multirow{2}{*}{$\begin{array}{l}t_{1 / 2} \text { of } \\
\text { pseudo-second } \\
\text { order }(\mathrm{h})\end{array}$} \\
\hline & & $\begin{array}{l}\text { Pseudo-first } \\
\text { order }\end{array}$ & $\begin{array}{l}\text { Pseudo-second } \\
\text { order }\end{array}$ & $\begin{array}{l}\text { Higuchi } \\
\text { model }\end{array}$ & $\begin{array}{l}\text { Hixson-Crowell } \\
\text { model }\end{array}$ & $\begin{array}{l}\text { Korsmeyer-Peppas } \\
\text { model }\end{array}$ & & \\
\hline \multirow[t]{2}{*}{ Hexaconazole } & CHDEN5 & 0.8095 & 0.9977 & 0.7919 & 0.4395 & 0.8677 & 0.0108 & 53 \\
\hline & CHDEN20 & 0.6775 & 0.9998 & 0.7919 & 0.3576 & 0.8677 & 0.0108 & 66 \\
\hline \multirow[t]{2}{*}{ Dazomet } & CHDEN5 & 0.4697 & 0.9997 & 0.8068 & 0.2787 & 0.8712 & 0.0132 & 15 \\
\hline & CHDEN20 & 0.2183 & 0.9997 & 0.8068 & 0.1126 & 0.8712 & 0.0132 & 19 \\
\hline
\end{tabular}

in Fig. 9B-F and 10B-F, respectively. The linear form in the firstorder kinetics model is given in eqn (4), where $q_{\mathrm{e}}$ and $q_{t}$ are the quantities of fungicides released at equilibrium and any time $(t)$, respectively, and $\mathrm{K}_{1}$ is the rate constant for the pseudo-firstorder release kinetics. The linear form in the second-order kinetics model can be represented by eqn (5), where $K_{2}$ is the rate constant of the pseudo-second-order release kinetics. The Higuchi model (eqn (6)) describes the increased release of the fungicides from the nanoparticles with an increasing square root of time, where $K_{\mathrm{H}}$ is the Higuchi rate constant. The HixsonCrowell model (eqn (7)) provides a relationship between the cube root of the dazomet that remains in the nanoparticles as a function of time, where $K_{\mathrm{HC}}$ is the Hixson-Crowell rate constant, $M_{\mathrm{o}}$ is the initial quantity of the fungicides in the nanoparticles and $q_{t}$ is the quantity released at time $t$. The Korsmeyer-Peppas (eqn (8)) model provides a relationship between the log of the percentage of the fungicides released and the log of time, where $q_{\infty}$ is the release at infinite time and $n$ is the release exponent.

$$
\ln \left(q_{\mathrm{e}}-q_{t}\right)=\ln q_{\mathrm{e}}-K_{1} t
$$

$$
\begin{gathered}
t / q_{t}=1 / K_{2} q_{\mathrm{e}}^{2}+t / q_{\mathrm{e}} \\
q_{t}=K_{\mathrm{H}} \sqrt{ } \\
\sqrt[3]{M_{0}}-\sqrt[3]{q_{t}}=K_{\mathrm{HC}} t \\
q_{t} / q_{\infty}=K t^{n}
\end{gathered}
$$

The calculated correlation coefficient $\left(R^{2}\right)$, the rate constant $(K)$ and $t_{1 / 2}$ values (Table 2) of the release data reveal that the release kinetics of both CHDEN5 and CHDEN20 fitted well to the pseudo-second-order kinetics for both fungicides compared to the other models used in this work. Hence indicating that the overall reactions are dependent upon the ion exchange between the fungicide molecules and the release medium at the time of release and at the equilibrium. ${ }^{38,39}$ On the other hand, the results revealed the ability of hexaconazole to sustain for a longer time when encapsulated in chitosan, compared to the dazomet. This finding is also in an agreement with previous studies done by our group on the single-loaded systems of chitosan-hexaconazole nanoparticles (CHEN) ${ }^{29}$ and chitosan-
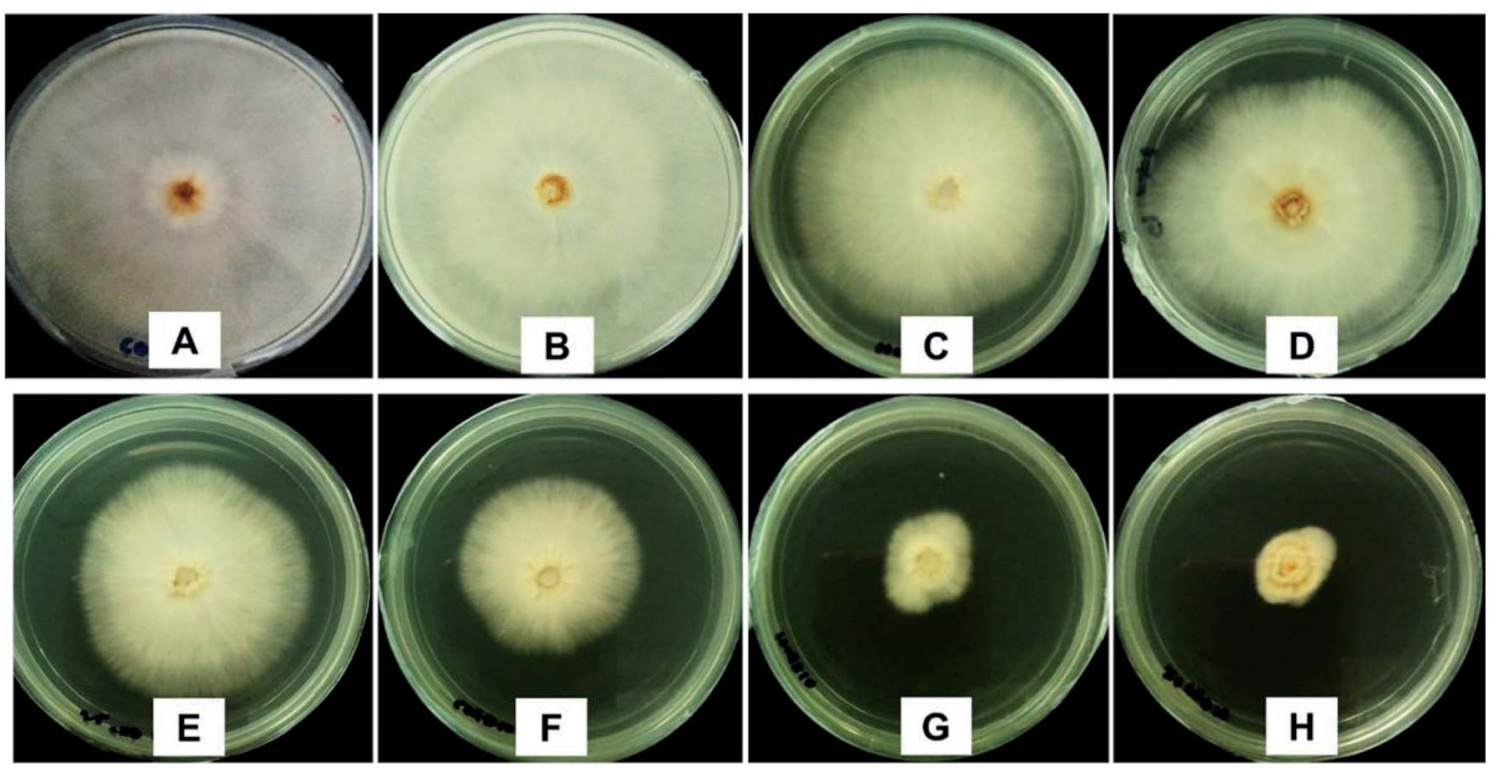

Fig. 11 Anti-fungal effect on G. boninense of the control (A), $10 \mathrm{ppb}$ of chitosan (B), $10 \mathrm{ppb}$ of pure hexaconazole (C), $10 \mathrm{ppb}$ of pure dazomet (D), $10 \mathrm{ppb}$ of chitosan-hexaconazole-dazomet nanoparticles prepared at various concentrations of TPP (E) $2.5 \mathrm{mg} \mathrm{L}^{-1}$, (F) $5 \mathrm{mg} \mathrm{mL}^{-1}$, (G) $10 \mathrm{mg}^{\circ}$ $\mathrm{mL}^{-1}$ and $(\mathrm{H}) 20 \mathrm{mg} \mathrm{mL}^{-1}, 7$ days after incubation at $28 \pm 2{ }^{\circ} \mathrm{C}$. 

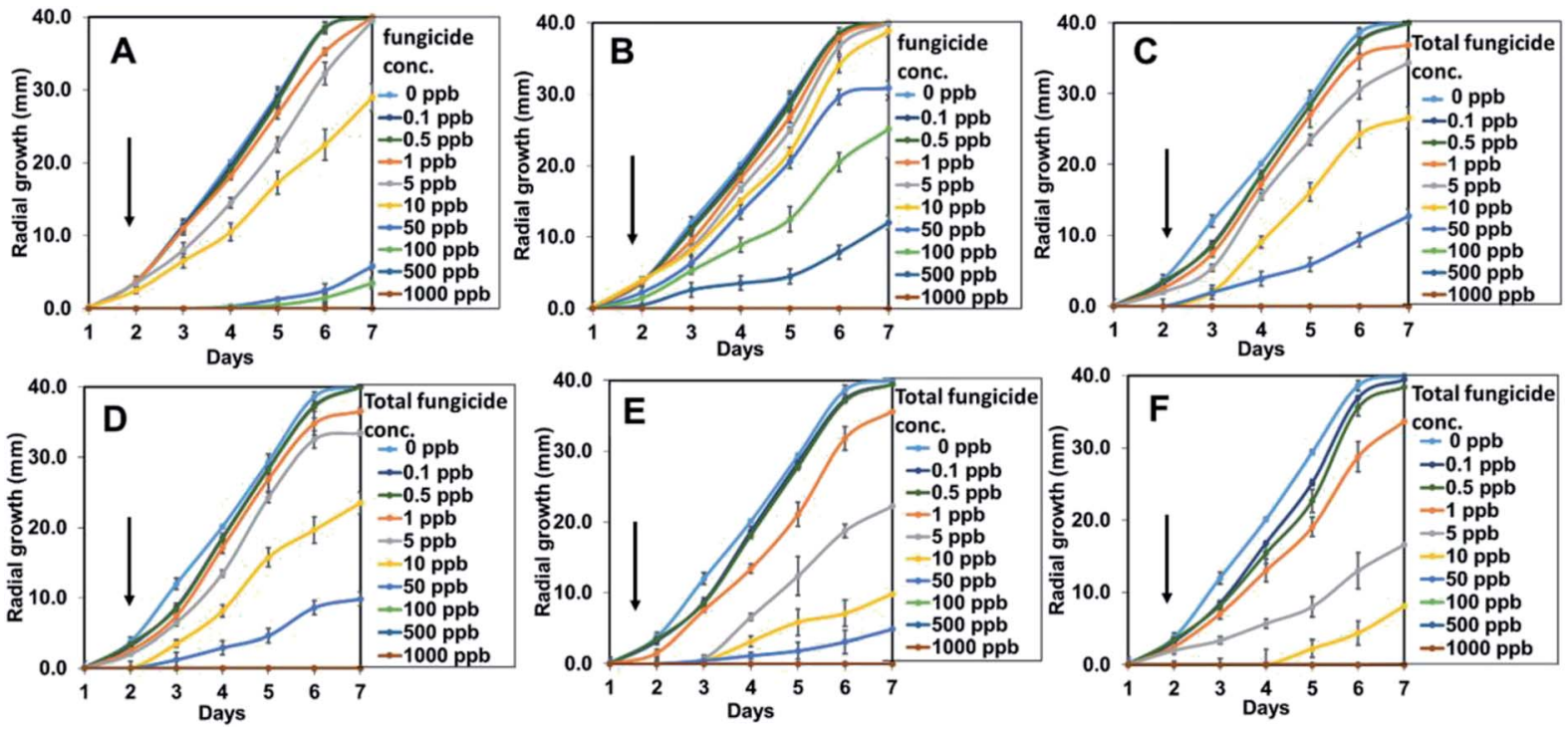

Fig. 12 Growth curves of G. boninense incubated in pure hexaconazole (A), pure dazomet (B), and chitosan-hexaconazole-dazomet nanoparticles prepared at various concentrations of TPP (C) $2.5 \mathrm{mg} \mathrm{L}^{-1}$, (D) $5 \mathrm{mg} \mathrm{mL}^{-1}$, (E) $10 \mathrm{mg} \mathrm{mL}^{-1}$ and (F) $20 \mathrm{mg} \mathrm{mL}^{-1}$ at $28 \pm 2{ }^{\circ} \mathrm{C}$ and at increasing concentrations of $0-1000 \mathrm{ppb}$ at day 1 until 7. Black arrows represent the increasing of the total fungicide concentration and the error bars represent standard deviation of the mean.

dazomet nanoparticles (CDEN). ${ }^{30}$ Moreover, in contrast with the single encapsulation of CHEN and CDEN, the dual encapsulation of CHDEN showed a prolonged release of fungicides for up to twice the release time.

\section{In vitro antifungal activity assay in the inhibition on $G$. boninense}

The in vitro antifungal studies were done under several conditions: a control, where the mycelia were plated on the PDA with only solvent and the host (chitosan), the guests (pure hexaconazole and pure dazomet), and the synthesized nanoparticles; CHDEN2.5, CHDEN5, CHDEN10, and CHDEN20. The inhibitory effect of the pure fungicides and the synthesized nanoparticles on $G$. boninense was evaluated based on the inhibition rate and the calculated $\mathrm{EC}_{50}$ value. A higher inhibition rate showed better antifungal activity against $G$. boninense. On the contrary, the lower the EC50 value, the more effective the fungicide is in combating the Ganoderma disease.

The antifungal activity was analyzed using the mycelia growth method. As shown in Fig. 11, at 10 ppb, similar to the control, chitosan showed a negligible inhibitory effect as the maximum mycelial growth was achieved (radius of $40.0 \mathrm{~mm}$ ), while pure dazomet showed a low inhibitory effect $(38.8 \mathrm{~mm})$. However, pure hexaconazole showed a better inhibition with $29.0 \mathrm{~mm}$ mycelial growth. On the other hand, significant inhibitory effects could be seen for the synthesized nanoparticles. The significant inhibitory effects for the synthesized nanoparticles followed the order CHDEN2.5 > CHDEN5 > CHDEN10 $>$ CHDEN20 as the mycelial growth was much lower

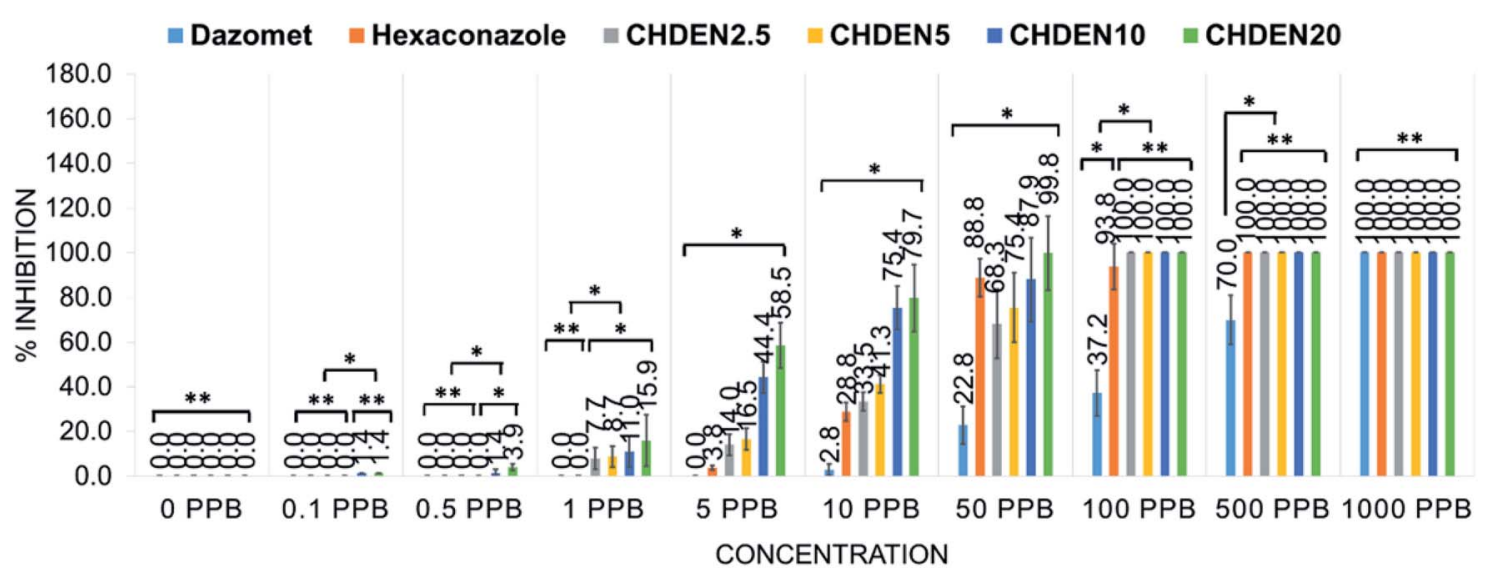

Fig. 13 Percentage inhibition of radial growth on G. boninense against concentration at day 7 incubation at $28 \pm 2{ }^{\circ} \mathrm{C}$ of chitosan, pure dazomet, pure hexaconazole and chitosan-hexaconazole-dazomet nanoparticles prepared at various concentrations of TPP where $* P<0.01$ (significant) and $* * P>0.5$ (not significant); the error bars represent standard deviation of the mean. 
Table 3 Calculated $\mathrm{EC}_{50}$ of chitosan, pure hexaconazole, pure dazomet and chitosan-hexaconazole-dazomet nanoparticles prepared at various concentrations of TPP on G. boninense at day 7 incubation at $28 \pm 2{ }^{\circ} \mathrm{C}$

Type of fungicides and nanoparticles

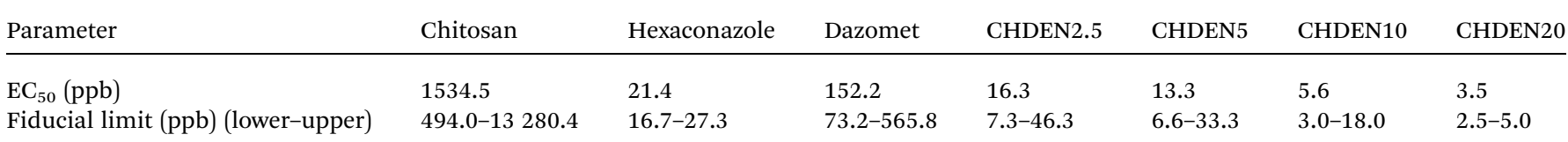

compared to the others $(26.6,23.5,9.8$ and $8.1 \mathrm{~mm}$, respectively).

These results also indicate that hexaconazole has a higher antifungal activity against $G$. boninense compared to dazomet. The hexaconazole mode of action is by blocking the ergosterol biosynthesis pathway which leads to the toxic sterol accumulation, and consequently results in fungal cell death. ${ }^{40}$ On the other hand, the dazomet mode of action is by the releasing of poisonous MITC gas which can inhibit the activity of the pathogenic fungi. ${ }^{41}$ This is presumably the reason why the antifungal activity of hexaconazole is higher because dazomet is only effective when it is in the gas form.

To obtain a better understanding, the mycelial mean radial growth was plotted against duration (day) (Fig. 12) and the percentages inhibition of radial growth (PIRG) at day 7 was calculated (Fig. 13). The pure hexaconazole showed a significant inhibitory effect starting from 5 ppb (1.3\% PIRG) with complete inhibition $(100 \%)$ achieved at $500 \mathrm{ppb}$. Meanwhile, the pure dazomet showed significant inhibitory effects from $10 \mathrm{ppb}$ (2.8\% PIRG) and $100 \%$ inhibition at $1000 \mathrm{ppb}$. Moreover, remarkable inhibitory effects of the synthesized chitosan-hexaconazole-dazomet nanoparticles were achieved. CHDEN10 and CHDEN20 started to show inhibition on $G$. boninense growth at a very low concentration of 0.1 and $0.5 \mathrm{ppb}$. Meanwhile, CHDEN2.5 and CHDEN5 begin to show their inhibition on $G$. boninense at $1 \mathrm{ppb}$. In addition, a complete inhibition
$(100 \%)$ was achieved at $100 \mathrm{ppb}$ for all the synthesized chitosan-hexaconazole-dazomet nanoparticles.

Moreover, the $\mathrm{EC}_{50}$ of the fungicides are presented in Table 3. Chitosan showed the highest $\mathrm{EC}_{50}$ value with $1534.5 \mathrm{ppb}$, followed by pure dazomet and pure hexaconazole with values of 152.2 and $21.4 \mathrm{ppb}$, respectively. Besides, the synthesized nanoparticles showed a remarkably better antifungal activity on $G$. boninense with lower $\mathrm{EC}_{50}$ values. In general, in all the systems, parallel to the effect of TPP on the particle size, the smaller particle sizes of the chitosan-fungicide nanoparticles resulted in lower $\mathrm{EC}_{50}$ values in which there was higher antifungal activity on $G$. boninense, which follows the order: CHDEN2.5 > CHDEN5 > CHDEN10 > CHDEN20 with 16.3, 13.3, 5.6, and $3.5 \mathrm{ppb}$, respectively.

Furthermore, the relationship between the particle size of the synthesized chitosan-hexaconazole-dazomet nanoparticles and $\mathrm{EC}_{50}$ value as well as the percentage of inhibition of mean mycelial growth of $G$. boninense was plotted (Fig. 14). Both methods confirmed that the decrease in particle size logarithmically decreased the $\mathrm{EC}_{50}$ value (Fig. 14A), and increased the inhibition percentage (Fig. 14B). This shows that the smaller particle size of the synthesized chitosan-hexaconazole-dazomet nanoparticles had a better antifungal activity against $G$. boninense which is due to the larger surface area that can be contacted with the fungus cell. ${ }^{42}$
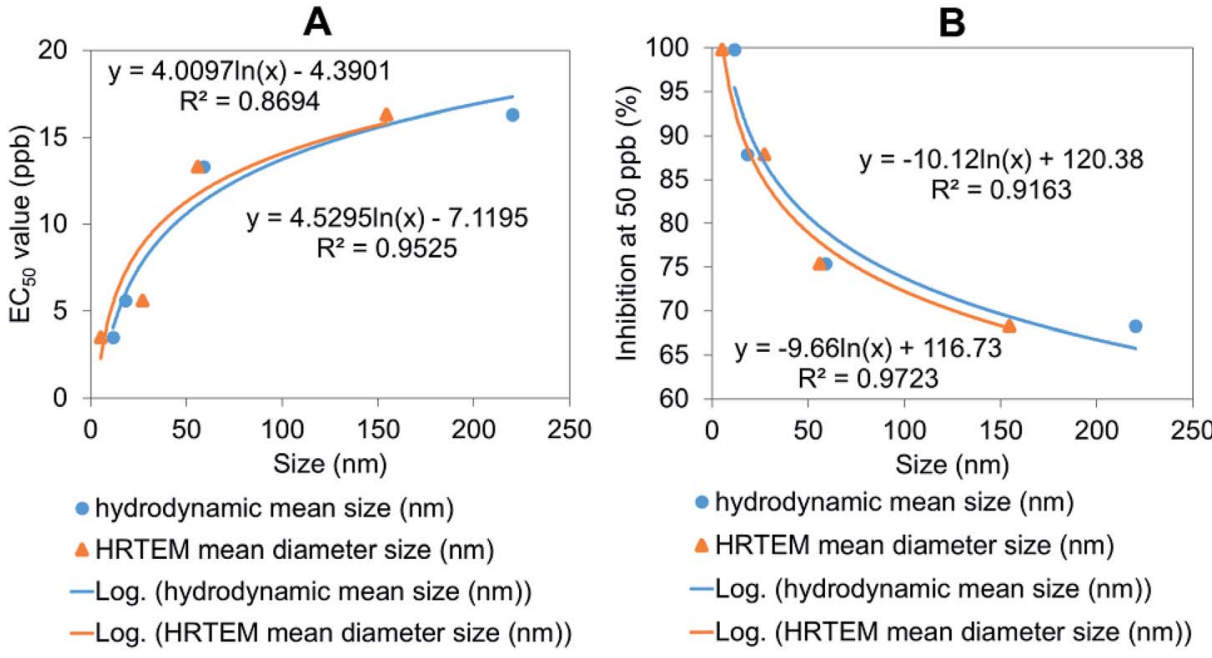

Fig. 14 The relationship between the hydrodynamic mean particle size distribution and HRTEM mean particle size distribution of the synthesized chitosan-hexaconazole-dazomet nanoparticles to (A) their percentage inhibition at $50 \mathrm{ppb}$ and (B) the calculated $\mathrm{EC}_{50}(\mathrm{ppb})$ value on $\mathrm{G}_{\text {. }}$ boninense. 
In comparison to our earlier work on single loaded systems of hexaconazole ${ }^{29}$ and dazomet $^{30}$ into the chitosan nanoparticles, the results revealed a synergistic effect in the codelivery of hexaconazole and dazomet in the inhibition of $G$. boninense growth. The lowest $\mathrm{EC}_{50}$ values achieved for single loaded hexaconazole and dazomet in chitosan nanoparticles at $20 \mathrm{mg} \mathrm{mL} \mathrm{m}^{-1}$ of TPP were $4.6 \pm 1.6$ and $13.7 \pm 1.8 \mathrm{ppb}$, respectively. Meanwhile, the dual loading of fungicides managed to enhance its fungicidal effect by up to four times.

\section{Conclusions}

In summary, four types of chitosan-hexaconazole-dazomet nanoparticles were successfully synthesized at four different sizes: $155,56,27$, and $5 \mathrm{~nm}$. The particle size of the agronanoparticles can be modified by varying the sodium TPP concentrations, where the increase of sodium TPP resulted in a smaller particle size. In addition, the synthesized agronanoparticles showed better thermal stability compared to their counterparts, pure dazomet, and pure hexaconazole. Moreover, the co-delivery of fungicide showed a sustained release with the release time of hexaconazole and dazomet up to 118 and 42 hours, respectively. Furthermore, the plot of the relationship between the particle size of the synthesized chitosan-hexaconazole-dazomet nanoparticles and $\mathrm{EC}_{50}$ value as well as the percentage of inhibition of the mean mycelial growth of $G$. boninense revealed a synergistic effect of dual-loaded fungicides, where the decrease in particle size logarithmically decreased the $\mathrm{EC}_{50}$ value as well as increased the inhibition percentage of mean mycelial growth of $G$. boninense. The proposed agronanoparticles were able to give a longer efficiency time and had a low toxicity but a high antifungal activity against $G$. boninense, which make them a promising candidate to be applied in the control and treatment of basal stem rot disease in oil palms.

\section{Conflicts of interest}

The authors declare no conflicts of interest.

\section{Acknowledgements}

The research was funded by Universiti Putra Malaysia (UPM) and the Ministry of Higher Education of Malaysia under the LRGS-NanoMITe program, vote no. 9443100 and 5526300 and GP-IPS, vote no. 9647400 . F. N. M. would like to thank UPM for a graduate research fellowship (GRF) and the Sime Darby Foundation for a scholarship. Thanks to the Malaysian Palm Oil Board (MPOB) for the G. boninense culture and laboratory facilities for the in vitro analysis studies.

\section{References}

1 S. D. Plantation, Sime Darby Plantation, 2014.

2 T. C. Hai, The palm oil industry in Malaysia, WWF, Malaysia, 2002.

3 C. Carter, W. Finley, J. Fry, D. Jackson and L. Willis, Eur. J. Lipid Sci. Technol., 2007, 109, 307-314.
4 R. Paterson, Crop Protect., 2007, 26, 1369-1376.

5 D. Ariffin, A. Idris and G. Singh, Ganoderma Dis. Perenn. Crop., 2000, pp. 49-68.

6 A. Idris, A. Kushairi, S. Ismail and D. Ariffin, J. Oil Palm Res., 2004, 16, 12-18.

7 A. Idris, R. Arifurrahman and A. dan Kushairi, MPOB TS Inf. Ser., 2010.

8 A. Idris, R. Arifurrahman and D. Kushairi, PIPOC (Agriculture, Biotechnology and Sustainability), Malaysia, 2009.

9 A. Idris and S. Maizatul, MPOB TS Inf. Ser., 2012, vol. 107.

10 J. Zhou, J. Li, J. Li, G. Ren, Y. Ren and H. Ma, Chem. Res. Chin. Univ., 2017, 1-5.

11 J. T. i. Blasco, T. Grote, M. Scherer, R. Stierl, S. Strathmann and U. Schofl, US Pat., US20070066629A1, 2007.

12 L. Huang, D. Lu, P. Zhang, J. Diao and Z. Zhou, Chirality, 2012, 24, 610-614.

13 S. Khalfallah, U. Menkissoglu-Spiroudi and H. A. Constantinidou, J. Agric. Food Chem., 1998, 46, 16141617.

14 M. Austerweil, B. Steiner and A. Gamliel, Phytoparasitica, 2006, 34, 491-501.

15 D. Wang, S. W. Fraedrich, J. Juzwik, K. Spokas, Y. Zhang and W. C. Koskinen, Pest Manage. Sci., 2006, 62, 263-273.

16 F. I. Taylor, D. Kenyon and S. Rosser, Plant Soil, 2014, 382, 281-289.

17 R. Troncoso, C. Espinoza, A. Sánchez-Estrada, M. Tiznado and H. S. García, Food Res. Int., 2005, 38, 701-708.

18 T. Degenkolb and A. Vilcinskas, Appl. Microbiol. Biotechnol., 2016, 100, 3799-3812.

19 Z. Maznah, M. Halimah, S. Ismail and A. S. Idris, Environ. Sci. Pollut. Res., 2015, 22, 19648-19657.

20 P. M. White, T. L. Potter and A. K. Culbreath, Sci. Total Environ., 2010, 408, 1393-1402.

21 L. F. Fraceto, R. Grillo, G. A. de Medeiros, V. Scognamiglio, G. Rea and C. Bartolucci, Front. Environ. Sci., 2016, 4, 20.

22 A. Ditta, M. Arshad and M. Ibrahim, in Nanotechnology and plant sciences, Springer, 2015, pp. 55-75.

23 M. Sharon, A. K. Choudhary and R. Kumar, J. Phytol., 2010, 2, 83-92.

24 A. Ditta, Adv. Nat. Sci.: Nanosci. Nanotechnol., 2012, 3, 033002.

25 A. J. Anderson, Res. Plant Dis., 2018, 24, 99-112.

26 S. M. Ouda, Res. J. Microbiol., 2014, 9, 34-42.

27 A. El Hadrami, L. R. Adam, I. El Hadrami and F. Daayf, Mar. Drugs, 2010, 8, 968-987.

28 V. Sharma, S. Anandhakumar and M. Sasidharan, Mater. Sci. Eng., C, 2015, 56, 393-400.

29 F. N. Maluin, M. Z. Hussein, N. A. Yusof, S. Fakurazi, A. S. Idris, N. H. Zainol Hilmi and L. D. Jeffery Daim, Molecules, 2019, 24, 2498.

30 F. N. Maluin, M. Z. Hussein, N. A. Yusof, S. Fakurazi, A. S. Idris, N. H. Z. Hilmi and L. D. Jeffery Daim, Int. J. Mol. Sci., 2019, 20, 2247.

31 A. S. Hanafy, R. M. Farid and S. S. ElGamal, Drug Dev. Ind. Pharm., 2015, 41, 2055-2068. 
32 R. Subbiah, P. Ramalingam, S. Ramasundaram, K. Park, M. K. Ramasamy and K. J. Choi, Carbohydr. Polym., 2012, 89, 1289-1297.

33 S. H. Hussein-Al-Ali, A. Kura, M. Z. Hussein and S. Fakurazi, Polym. Compos., 2018, 39, 544-552.

34 S. Mohan, N. Sundaraganesan and J. Mink, Spectrochim. Acta, Part A, 1991, 47, 1111-1115.

35 I. F. Mustafa, M. Z. Hussein, I. A. Seman, N. H. Z. Hilmi and S. Fakurazi, ACS Sustainable Chem. Eng., 2018, 6, 1606416072.

36 I. F. Mustafa, M. Z. Hussein, B. Saifullah, A. S. Idris, N. H. Z. Hilmi and S. Fakurazi, J. Agric. Food Chem., 2018, 66, 806-813.
37 B. Hu, C. Pan, Y. Sun, Z. Hou, H. Ye, B. Hu and X. Zeng, J. Agric. Food Chem., 2008, 56, 7451-7458.

38 Y. Ho and G. McKay, Process Saf. Environ. Prot., 1998, 76, 332-340.

39 J. M. Tan, G. Karthivashan, S. A. Gani, S. Fakurazi and M. Z. Hussein, J. Mater. Sci.: Mater. Med., 2016, 27, 26.

40 W. Köllerm, Encyclopedia of Agrochemicals, 2003.

41 P. P. Reddy, in Recent advances in crop protection, Springer, 2012, pp. 37-60.

42 F. Raimondi, G. G. Scherer, R. Kötz and A. Wokaun, Angew. Chem., Int. Ed., 2005, 44, 2190-2209. 